\title{
Bone Cement-Augmented Percutaneous Screw Fixation for Malignant Spinal Metastases : Is It Feasible?
}

Pius Kim, M.D., Seok Won Kim, M.D., Ph.D.

Department of Neurosurgery, College of Medicine, Chosun University, Gwangju, Korea

Objective : We evaluated the validity of bone cement-augmented percutaneous screw fixation for treating malignant spinal metastases.

Methods : Between 2011 and 2015, 14 patients (eight men and six women) who underwent bone cement-augmented percutaneous screw fixation for malignant spinal metastases were enrolled in this study. Their life expectancy was considered to be more than one month and less than one year, based on the revised Tokuhashi scoring system. Clinical findings including the back pain scale score, functional outcome, procedure related complications, and survival were assessed preoperatively, postoperatively, and then six months after the procedure.

Results : Twelve of the patients (86\%) survived up to six months after the procedure. Three required mini-open decompressive laminectomy for severe epidural compression. Bone cement-augmented percutaneous screw fixation was performed one level above, one level below, and at the pathologic level itself. The mean operation time was 60 minutes (45-180) and blood loss was less than $100 \mathrm{~mL}$. Prior to surgery, the mean pain score on the visual analogue scale was 8.8 , while one month after the procedure, it had reduced to 3.0; this improvement was maintained until the six-month assessment in the surviving patients. All patients were able to sit within the first two days after surgery, and no patient experienced neurological deterioration at the one-month follow up after the surgery. No patient experienced screw loosening during the six months of follow-up. Asymptomatic cement leakage into the epidural space was observed in two patients, but no major complications were observed.

Conclusion : For selected patients with malignant spinal metastases, bone cement-augmented percutaneous screw fixation can provide significant pain relief and improve quality of life.

Key Words : Screw · Metastasis · Percutaneous.

\section{INTRODUCTION}

The spinal column is the most common site for malignant bone metastasis. The expected life span of patients diagnosed with malignant spinal metastasis varies from several months to years depending on the aggressiveness of the primary tu- mor and the visceral involvement ${ }^{4)}$. For these reasons, the surgical goal for spinal metastasis is pain relief and restoration of physical function during survival. However, traditional open surgery involving decompressive laminectomy with long level screw fixation and bone fusion carries high morbidity and mortality rates in patients with spinal metastases ${ }^{15)}$.

- Received : September 26, 2016 •Revised : November 7, 2016 •Accepted : November 26, 2016

- Address for reprints : Seok Won Kim, M.D., Ph.D.

Department of Neurosurgery, College of Medicine, Chosun University, 365 Pilmun-daero, Dong-gu, Gwangju 61453, Korea

Tel : +82-62-220-3126, Fax : +82-62-227-4575, E-mail : chosunns@chosun.ac.kr

This is an Open Access article distributed under the terms of the Creative Commons Attribution Non-Commercial License (http://creativecommons.org/licenses/by-nc/4.0) which permits unrestricted non-commercial use, distribution, and reproduction in any medium, provided the original work is properly cited. 
Identifying minimally invasive procedures with low morbidity that can effectively treat spinal metastasis is essential for this population of patients with a limited life expectancy.

Bone cement augmentation procedures such as vertebroplasty or balloon kyphoplasty are sometimes helpful in cancer patients with limited anticipated survival or who are poor surgical candidates ${ }^{1)}$.

However, vertebroplasty or kyphoplasty alone are usually not effective for mechanically unstable pathologic fractures involving the middle and posterior vertebral column. In such cases, patients usually require posterior screw fixation for structural stabilization.

To our knowledge, there are few reports that have examined the safety and efficacy of less invasive, bone cement-augmented percutaneous screw fixation for the treatment of malignant spinal metastasis ${ }^{10)}$.

The purpose of this study was to evaluate the efficacy of less invasive technique for the treatment of malignant spinal metastasis and determine whether quality of life after this technique is meaningful.

\section{MATERIAL AND METHODS}

From 2011 to 2015, fourteen patients (eight males and six females) with malignant spine metastases were enrolled in this study.

Patients were eligible for inclusion if they had histologic proof of malignancy and intractable back pain with or without radiating pain due to an impending metastatic pathologic fracture. These include mechanical instability, radioresistant metastatic tumor and intractable back pain unresponsive to continuous opioids. For the assessment of tumor spread or severity, the revised Tokuhashi scoring system, which considers general condition, tumor type, visceral metastases, bone metastases, performance scale and spinal cord palsy, was used ${ }^{14)}$. In patients with a total score less than 11 (who had a predicted survival period, of more than one month and less than one year) assessed by the medical oncologist were selected.

All of the patients had single level lesion involving T9-to L2.

Patients with non-metastatic primary spinal tumors were excluded from this study and patients who had multiple spinal metastases or severe neurologic deficits such as paraplegia were also excluded from this study.

\section{Surgical procedure}

After a thorough explanation of the procedure, the patients were anesthetized and placed prone on a radiolucent table.

The bone cement-augmented percutaneous screw fixation was confined to the one level above, one level below, and the tumor involved level itself, using the percutaneous pedicle screw system (Viper ${ }^{\circledR}$ Synthes, Switzerland). Three of the patients needed mini-open decompression due to epidural cord compression extending into the unilateral pedicle and facet. In these patients, unilateral transpedicular screw fixation was performed at the intact contralateral side. Bone cement-augmentation was performed using polymethylmethacrylate (PMMA), which was injected under C-arm guidance through a vertebroplasty needle. Approximately $2.5 \mathrm{~mL}$ of PMMA was injected through each pedicle.

The patients' demographics and medical condition before and after surgery, imaging data, procedure related complications, adjuvant treatments, and functional status were analyzed (Table 1).

\section{Statistical analysis}

Statistical analysis was performed using SAS 6.12 (SAS Institute, Inc., Cary, NC, USA).

Mann-Whitney's U test was used to investigate the comparisons between the different time points. $p$ values $<0.05$ were accepted as statistically significant.

\section{RESULTS}

A total of 14 patients underwent bone cement-augmented percutaneous screw fixation for malignant spinal metastasis. Table 1 summarizes the patients' demographic data. Most of the fractures occurred at the low thoracic and thoracolumbar junction. The anatomical distribution of the metastatic vertebra in this study was as follows : T9 $(n=1)$, T10 $(n=1)$, T11 $(n=5)$, T12 ( $n=3)$, L1 $(n=2)$ and L2 $(n=2)$. The patients' mean age was 64.5 years (range $45-78$ years). The mean operation time was 60 minutes (45-180 minutes) and none of the patients needed a drainage catheter or blood transfusion. The most common primary cancer was hepatobiliary cancer in 7 cases, followed by lung, colon and breast cancer in two cases, respectively.

All of the patients were transferred to the hemato-oncological department for various adjuvant treatments after surgery. 
Table 1. Characteristics of the patients

\begin{tabular}{|c|c|c|c|c|c|c|c|c|c|c|c|}
\hline Case & $\begin{array}{c}\text { Age/ } \\
\text { gender }\end{array}$ & Level & Primary site & $\begin{array}{c}\text { Revised } \\
\text { Tokuhashi score }\end{array}$ & $\begin{array}{l}\text { Adjuvant } \\
\text { therapy }\end{array}$ & $\begin{array}{l}\text { Survival } \\
\text { (months) }\end{array}$ & $\begin{array}{c}\text { VAS } \\
\text { (preop) }\end{array}$ & $\begin{array}{l}\text { VAS } \\
(1 \mathrm{mo})\end{array}$ & $\begin{array}{l}\text { VAS } \\
(6 \mathrm{mo})\end{array}$ & $\begin{array}{l}\text { Mean } \\
\text { BMD }\end{array}$ & $\begin{array}{l}\text { Decom- } \\
\text { pression }\end{array}$ \\
\hline 1 & $54 / \mathrm{M}$ & T9 & Hepatobiliary & 6 & RT & 7 & 9 & 2 & - & -2.8 & Yes \\
\hline 2 & $74 / \mathrm{M}$ & L2 & Colon & 10 & RT & 6 & 10 & 3 & 3 & -3.4 & Yes \\
\hline 3 & $65 / F$ & $\mathrm{~T} 11$ & Hepatobiliary & 8 & RT & 6 & 8 & 4 & 3 & -3.1 & No \\
\hline 4 & $63 / F$ & L1 & Cervix & 7 & Chemo & 9 & 9 & 2 & 2 & -3.2 & No \\
\hline 5 & $68 / M$ & $\mathrm{~T} 12$ & Hepatobiliary & 8 & RT, chemo & 10 & 7 & 2 & 2 & -2.5 & No \\
\hline 6 & $78 / \mathrm{M}$ & $\mathrm{T} 11$ & Adenoca of lung & 6 & RT & 8 & 9 & 3 & 3 & -4.3 & No \\
\hline 7 & $50 / \mathrm{M}$ & $\mathrm{T} 11$ & Hepatobiliary & 8 & RT & 4 & 9 & 4 & - & -3.5 & No \\
\hline 8 & $74 / F$ & $\mathrm{~T} 10$ & Colon & 10 & - & 8 & 10 & 5 & 5 & -3.2 & No \\
\hline 9 & $65 / M$ & L1 & Hepatobiliary & 8 & RT & 10 & 10 & 4 & 2 & -2.9 & Yes \\
\hline 10 & $69 / F$ & $\mathrm{~T} 12$ & Breast & 8 & RT & 11 & 8 & 3 & 3 & -3.1 & No \\
\hline 11 & $74 / M$ & $\mathrm{~T} 12$ & Hepatobiliary & 7 & - & 7 & 7 & 2 & 3 & -2.5 & No \\
\hline 12 & $62 / M$ & $\mathrm{~T} 11$ & Hepatobiliary & 7 & - & 7 & 8 & 3 & 4 & -3.3 & No \\
\hline 13 & 59/F & $\mathrm{T} 11$ & Breast & 8 & Chemo & 15 & 7 & 3 & 2 & -3.9 & No \\
\hline 14 & $45 / F$ & $\mathrm{~L} 2$ & Adenoca of lung & 7 & RT, chemo & 4 & 8 & 2 & - & -2.6 & No \\
\hline
\end{tabular}

VAS : visual analogue scale-back pain, mo : month, BMD : bone mineral densitometry, RT : radiotherapy, Adenoca : adenocarcinoma

\section{Clinical outcome}

All patients experienced significant pain relief after surgery.

Preoperatively, six of the patients were ambulatory, four patients were able to walk with assistance, two patients were wheel-chair bound, and two patients were bed ridden due to intractable back pain. All of the patients, even the patients who had previously been bed ridden, could sit within the first two days after surgery wearing a thoracolumbosacral orthosis.

At the one month postoperative follow up, six of the patients were ambulatory, four patients could walk with assistance, and four patients were able to sit and were wheel-chair bound.

No mortality was observed during the first month after surgery, but two patients who had lung cancer and hepatocellular carcinoma for their primary tumor type with accompanying visceral metastases died at 4 months after the index surgery.

Within the first 3 months postoperatively, two of the patients who underwent mini-open decompressive laminectomy showed neurologic deterioration due to local tumor progression. Prior to surgery, the patients' mean pain scale (visual analogue scale) was 8.8 . This score decreased to 3.0 one month after surgery. The improvement in the pain score was maintained at six months after surgery in the patients who survived (Fig. 1).

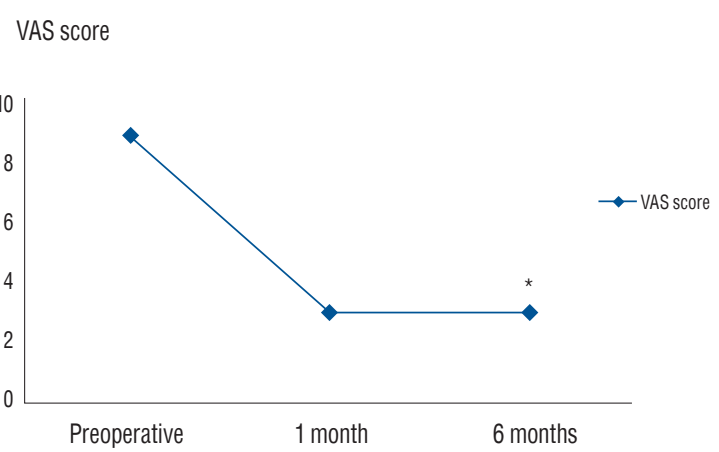

Fig. 1. Improvement of back pain scale. ${ }^{*} p<0.05$, preoperative versus 6 months. VAS was not obtainable in 2 patients who had died and 1 patient who showed hepatic coma at 6 months. VAS : visual analogue scale.

There was no screw loosening detected during the 6 months of follow-up. Asymptomatic cement leakage into the epidural space was observed in two patients, but no major complications such as cord compression or serious infection were observed (Fig. 2, 3).

\section{DISCUSSION}

It is known that about 70\% of patients with cancer develop metastatic disease and spinal involvement may occur in up to 

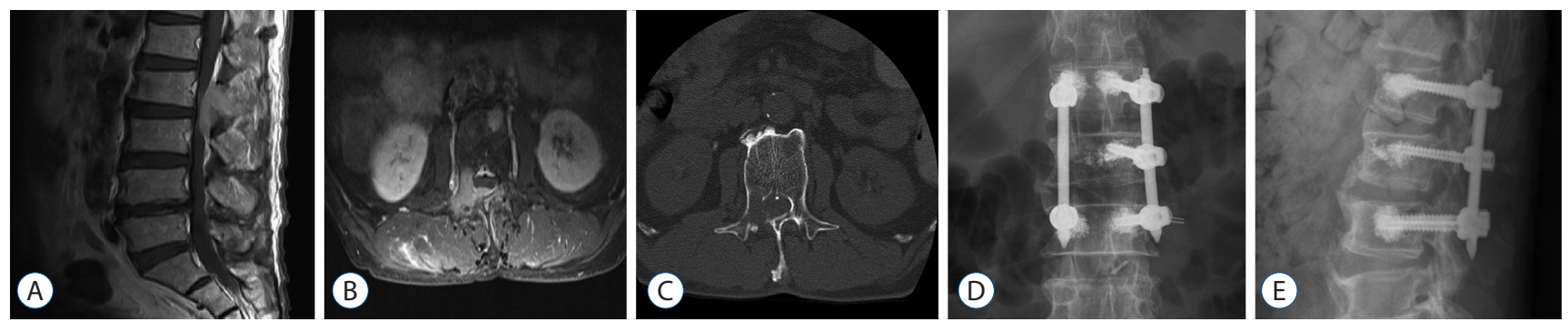

Fig. 2. Neuroimaging studies obtained in a patient with colon cancer that metastasized to the L2 level. A and B : Enhanced T1-weighted sagittal and axial images show significant involvement of posterior elements with epidural compression of thecal sac. $C$ : Computed tomography scan reveals destruction of the right $\mathrm{L} 2$ pedicle. $\mathrm{D}$ and $\mathrm{E}$ : Simple radiographs taken at 1 month after bone cement-augmented percutaneous short segment fixation demonstrate the three level stabilization.
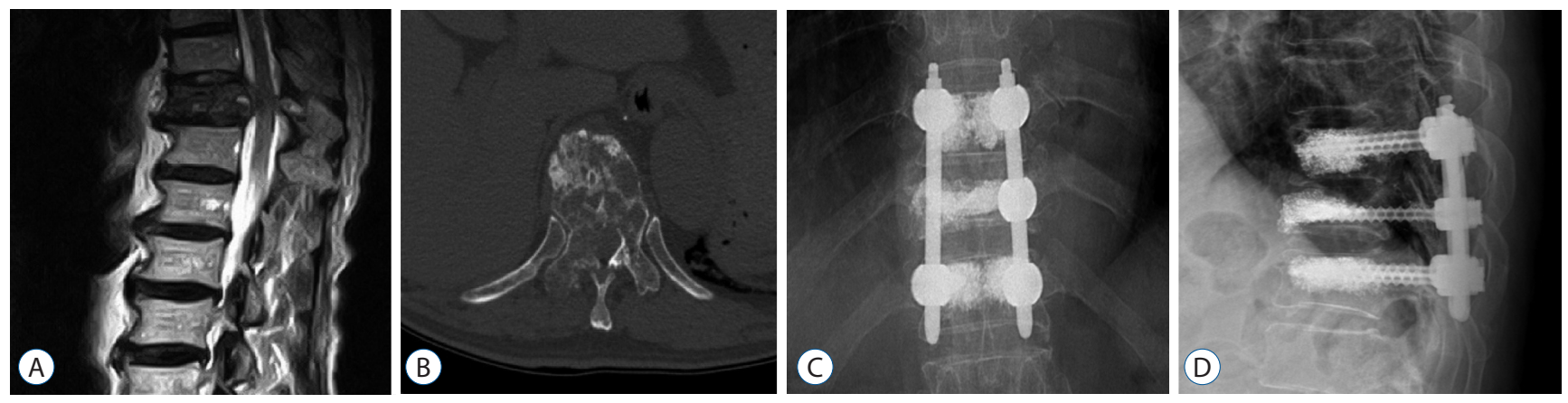

Fig. 3. Neuroimaging studies obtained in a patient with adenocarcinoma of lung that metastasized to the T11 level. A and B : T2- weighted sagittal image and computed tomography scan reveal severe cord compression and destruction of vertebral body and right pedicle at T11. C and D : Simple radiographs taken at 1 month after bone cement-augmented percutaneous short segment fixation show the three level stabilization.

$40 \%$ of patients with malignant cancer ${ }^{2,6)}$.

Metastatic spread to the spinal column can result in a number of sequelae including intractable pain and neurologic deficits. Treatment for malignant spinal metastasis is mainly palliative and it involves pain-reducing opioids, chemotherapy or radiotherapy. However, the indications of surgical treatment are becoming clearer. These include mechanical instability, significant neural compression, radioresistant metastatic tumors such as lung, colon or hepatobiliary and intractable back pain unresponsive to nonoperative treatments including opioids.

Although spine metastases involving the epidural compression should be operated on if possible, less invasive surgical procedures with low morbidity are extremely important treatment options in patients with a limited life expectancy.

Bone cement-augmentation procedures such as vertebroplasty or balloon kyphoplasty have been demonstrated to provide sufficient relief of intractable cancer related pain even in pathologic fractures showing epidural invasion ${ }^{5,12}$. However the injection of cement into the vertebral body usually has a limited role for mechanical support. They are usually not effective for the treatment of unstable spinal metastasis that extends into posterior elements such as pedicle or facet joint.

In such cases, application of rigid posterior instrumentation is usually needed to stabilize the spine due to cancer-related gross instability.

However, an extensive open surgery is not suitable for most patients with spinal metastasis in light of their limited life expectancy, because it carries high risk of complications and requires a long time to stabilize.

This series examined a minimally invasive surgery for patients with malignant spinal metastasis. The application of bone cement-augmented percutaneous screw fixation provided adequate pain relief and reliable support of the anterior and posterior elements in the cases that involved both anterior and posterior elements.

In patients with spinal metastasis, Kim et al.") reported on less invasive palliative surgery using percutaneous screw fixa- 
tion with vertebroplasty in 16 patients. The pain intensity and functional status were significantly improved without evident cement leakage causing spinal cord compression. Tancioni et al. ${ }^{13)}$ treated 25 patients with metastatic epidural spinal cord compression with a combination of decompressive laminectomy and percutaneous instrumentation of screws. Significant pain relief and improved neurological function were also achieved during survival.

In our series, we inserted percutaneous screws one level above, one level below, and at the collapsed level itself. In the three patients who required mini-open decompressive laminectomy for spinal cord compression involving the unilateral pedicle, percutaneous screw fixation was performed through the intact contralateral pedicle.

Most cancer patients are elderly and they usually have severe osteoporosis and poor bone quality, especially in the setting of spinal metastasis. Bone cement-augmented screw fixation has been shown in biomechanical and clinical studies to provide increased pullout loads in the osteoporotic spine ${ }^{3,11}$.

Most patients in our series do not tolerate long level fixation via traditional open surgery. They all had poor bone quality, vertebral collapse with tumor cell infiltration, and a predicted survival period of less than one year. Screw reinforcement using bone cement appeared to be a safe method to minimize pedicle screw stress through anterior support and an effective treatment to achieve pain relief to tumor-infiltrated bone. Moreover, bone cement injection into spine tumors can be used to relieve severe pain by mechanical stabilization of bone, destruction of sensitive nerves, and necrosis of tumor cells ${ }^{8,9)}$.

Most of the patients in our series required adjuvant radiotherapy or chemotherapy, and the advantage of this minimal invasive surgery via a small incision was that it did not influence the early initiation of postoperative adjuvant therapies.

However, in spite of our acceptable clinical outcome, the present study has some limitations. First, due to its rarity, we could only confirm our results in this rather small group of 14 patients who had malignant spinal metastasis.

Second, careful injection of bone cement is necessary because screw loosening and epidural cement leakage or retropulsion of tumor may occur more frequently in patients with osteoporotic spine or a highly vascular tumor.

\section{CONCLUSION}

Bone cement-augmented percutaneous screw fixation can be an alternative treatment to open surgery for selected patients with spinal metastasis.

Although temporary, it can improve quality of life by stabilizing both the anterior and posterior elements during survival.

\section{References}

1. Berenson J, Pflugmacher R, Jarzem P, Zonder J, Schechtman K, Tillman $J B$, et al. : Balloon kyphoplasty versus non-surgical fracture management for treatment of painful vertebral body compression fractures in patients with cancer : a multicentre, randomised controlled trial. Lancet Oncol 12 : 225-235, 2011

2. Böhm $P$, Huber $\mathrm{J}$ : The surgical treatment of bony metastases of the spine and limbs. J Bone Joint Surg Br 84 : 521-529, 2002

3. Burval DJ, McLain RF, Milks R, Inceoglu $S$ : Primary pedicle screw augmentation in osteoporotic lumbar vertebrae : biomechanical analysis of pedicle fixation strength. Spine (Phila Pa 1976) 32 : 1077-1083, 2007

4. Falicov A, Fisher CG, Sparkes J, Boyd MC, Wing PC, Dvorak MF : Impact of surgical intervention on quality of life in patients with spinal metastases. Spine (Phila Pa 1976) 31 : 2849-2856, 2006

5. Fourney DR, Schomer DF, Nader R, Chlan-Fourney J, Suki D, Ahrar K, et al. : Percutaneous vertebroplasty and kyphoplasty for painful vertebral body fractures in cancer patients. J Neurosurg 98(1 Suppl) : 21-30, 2003

6. Harrington $\mathrm{K}$ : Metastatic tumors of the spine : Diagnosis and treatment. J Am Acad Orthop Surg $1: 76-86,1993$

7. Kim CH, Chung CK, Sohn S, Lee S, Park SB : Less invasive palliative surgery for spinal metastases. J Surg Oncol 108 : 499-503, 2013

8. Kim SK, Chung JY, Cho CB, Choi HC : Percutaneous anterolateral vertebroplasty for a myelomatous pathologic fracture of the subaxial cervical spine : A case report. Korean J Spine 8 : 225-228, 2011

9. Lee CG, Kim SH, Kim DM, Kim SW : Giant cell tumor of upper thoracic spine. J Korean Neurosurg Soc 55 : 167-169, 2014

10. Park HY, Lee SH, Park SJ, Kim ES, Lee CS, Eoh W : Minimally invasive option using percutaneous pedicle screw for instability of metastasis involving thoracolumbar and lumbar spine : a case series in a single center. J Korean Neurosurg Soc 57 : 100-107, 2015

11. Sawakami K, Yamazaki A, Ishikawa S, Ito T, Watanabe K, Endo N : Polymethylmethacrylate augmentation of pedicle screws increases the initial fixation in osteoporotic spine patients. J Spinal Disord Tech 25 : 28 35,2012

12. Sun G, Li L, Jin P, Liu XW, Li M : Percutaneous vertebroplasty for painful spinal metastasis with epidural encroachment. J Surg Oncol 110 : $123-$ 128, 2014

13. Tancioni F, Navarria P, Pessina F, Marcheselli S, Rognone E, Mancosu P, et al. : Early surgical experience with minimally invasive percutaneous 
approach for patients with metastatic epidural spinal cord compression (MESCC) to poor prognoses. Ann Surg Oncol 19 : 294-300, 2012

14. Tokuhashi Y, Matsuzaki H, Oda H, Oshima M, Ryu J : A revised scoring system for preoperative evaluation of metastatic spine tumor prognosis.
Spine (Phila Pa 1976) 30 : 2186-2191, 2005

15. Zairi F, Arikat A, Allaoui M, Marinho P, Assaker R : Minimally invasive decompression and stabilization for the management of thoracolumbar spine metastasis. J Neurosurg Spine 17 : 19-23, 2012 